\title{
Dual antiplatelet therapy at discharge: Antiplatelet practice patterns after coronary artery bypass grafting, surgical anecdote is driving standard of care
}

\author{
Mark Helmers, MD, and Pavan Atluri, MD
}

\author{
From the Division of Cardiovascular Surgery, Department of Surgery, University of Pennsylvania, Philadelphia, \\ $\mathrm{Pa}$. \\ Disclosures: Authors have nothing to disclose with regard to commercial support. \\ Received for publication Oct 29, 2017; accepted for publication Oct 30, 2017; available ahead of print Nov 29 , \\ 2017. \\ Address for reprints: Pavan Atluri, MD, Division of Cardiovascular Surgery, Hospital of the University of Penn- \\ sylvania, Spruce St, 6 Silverstein Pavilion, Philadelphia 3400, PA (E-mail: Pavan.Atluri@uphs.upenn.edu). \\ J Thorac Cardiovasc Surg 2018;155:639-40 \\ $0022-5223 / \$ 36.00$ \\ Copyright $(\underset{2}{ } 2017$ by The American Association for Thoracic Surgery \\ https://doi.org/10.1016/j.jtcvs.2017.10.100
}

Thrombosis and platelet aggregation are key pathogenic mechanisms in acute coronary syndromes (ACS). Dual antiplatelet therapy (DAPT) with aspirin and a P2 $\mathrm{Y}_{12}$ inhibitor has been demonstrated to reduce death from cardiovascular causes, nonfatal myocardial infarction, and stroke after ACS. ${ }^{1-3}$ These large randomized controlled trials studied heterogeneous populations of patients with ACS treated with medical therapy, percutaneous coronary intervention, or coronary bypass grafting (CABG). The data supporting DAPT after CABG are less robust and limited to observational studies, subgroup analyses, and smaller randomized studies with surrogate end points. Nevertheless, the 2016 American College of Cardiology/ American Heart Association guidelines focused updates provide a class I recommendation for the resumption of DAPT after CABG in patients with ACS based on level C evidence. $^{4}$ Despite this, DAPT prescription in patients with ACS post-CABG is low. 5,6

In this issue of the Journal, Mori and colleagues ${ }^{7}$ analyzed the factors surrounding prescription of DAPT at hospital discharge in 572 patients who presented with ACS and underwent $\mathrm{CABG}$ at their institution between 2014 and $2016 .^{7}$ Despite recommendations, only $29 \%$ of patients were discharged on DAPT, a figure similar to the $27 \%$ reported from a Danish administrative database a decade earlier. ${ }^{5}$ Not surprisingly, rates of discharge on DAPT by surgeon varied from $0 \%$ to $62 \%$, and the operating surgeon had a significant effect on the odds of a patient being discharged on DAPT. Increased risk of bleeding, lack of familiarity with supporting data, and perceived lack of benefit after CABG were among the reasons for not restarting DAPT recent survey of cardiac surgeons practicing in Canada, where guidelines also recommend resumption of DAPT. ${ }^{6}$

At the center of this decision lies the tradeoff between preventing recurrent ischemia and risk of bleeding complications. In the multivariate logistic regression model

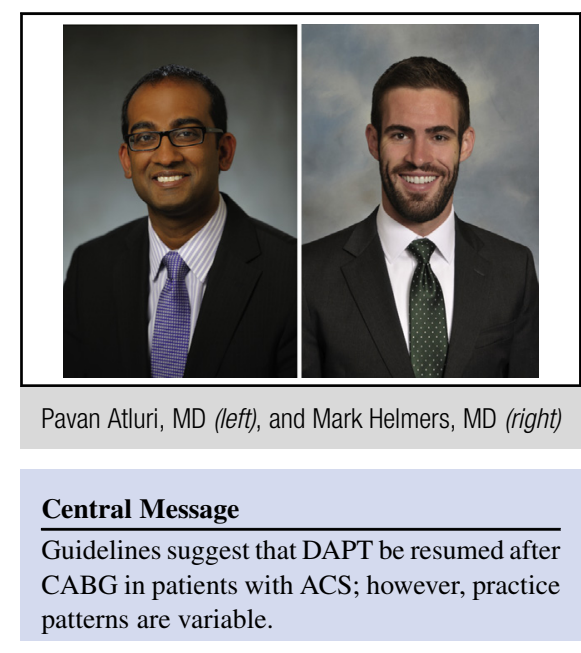

See Article page 632.

developed by Mori and colleagues, ${ }^{7} \mathrm{P} 2 \mathrm{Y}_{12}$ inhibitor use within 5 days before operation was associated with increased odds of DAPT use. This may be reflective of the lack of evidence and guidelines supporting the initiation of DAPT after CABG in those who did not receive a $\mathrm{P} 2 \mathrm{Y}_{12}$ inhibitor preoperatively. Furthermore, increasing age and anticoagulant use at discharge were associated with decreased odds of DAPT use, likely because of surgeon concern for increased bleeding risk. Last, off-pump CABG was associated with increased DAPT use. A hypercoagulable state may exist in the early postoperative period after off-pump $\mathrm{CABG},{ }^{8}$ and some evidence suggests increased graft patency ${ }^{9}$ and decreased symptom recurrence and adverse cardiac events ${ }^{10}$ to be benefits of DAPT after offpump CABG. As a counterpoint, although bleeding is a major comorbidity, it can largely be managed with less longterm adversity than graft thrombosis or similar adverse events. This brings into question the risk/benefit associated with not starting DAPT early.

In their study, Mori and colleagues ${ }^{7}$ shed important light on the practice patterns surrounding DAPT after CABG in patients with ACS. They furthermore illustrate the lack of standardized practice among our colleagues in this regard. Although randomized controlled trials are warranted to further elucidate the benefit of DAPT in this population, there is evidence to suggest a protective effect from recurrent ischemia. Surgeons should carefully weigh these against the risk of bleeding complications. 


\section{References}

1. Yusuf S, Zhao F, Mehta SR, Chrolavicius S, Tognoni G, Fox KK, Clopidogrel in Unstable Angina to Prevent Recurrent Events Trial Investigators. Effects of clopidogrel in addition to aspirin in patients with acute coronary syndromes without ST-segment elevation. N Engl J Med. 2001;345:494-502.

2. Wiviott SD, Braunwald E, McCabe CH, Montalescot G, Ruzyllo W, Gottlieb S, et al. Prasugrel versus clopidogrel in patients with acute coronary syndromes. $N$ Engl J Med. 2007;357:2001-15.

3. Wallentin L, Becker RC, Budaj A, Cannon CP, Emanuelsson H, Held C, et al. Ticagrelor versus clopidogrel in patients with acute coronary syndromes. $N$ Engl J Med. 2009;361:1045-57.

4. Levine GN, Bates ER, Bittl JA, Brindis RG, Fihn SD, Fleisher LA, et al. 2016 ACC/AHA Guideline Focused Update on Duration of Dual Antiplatelet Therapy in Patients with Coronary Artery Disease: A Report of the American College of Cardiology/American Heart Association Task Force on Clinical Practice Guidelines. J Thorac Cardiovasc Surg. 2016;134:e156-78.

5. Sørensen R, Abildstrøm SZ, Hansen PR, Hvelplund A, Andersson C, Charlot M, et al. Efficacy of post-operative clopidogrel treatment in patients revascularized with coronary artery bypass grafting after myocardial infarction. J Am Coll Cardiol. 2011;57:1202-9.

6. Yanagawa B, Ruel M, Bonneau C, Lee MM, Chung J, Al Shouli S, et al. Dual antiplatelet therapy use by Canadian cardiac surgeons. J Thorac Cardiovasc Surg. 2015;150:1548-54.e3.

7. Mori M, Shioda K, Yun JJ, Mangi AA, Darr U, Geirsson A. Pattern and predictors of dual antiplatelet use following coronary artery bypass graft surgery. J Thorac Cardiovasc Surg. 2018;155:632-8.

8. Raja SG, Akhtar S. Hypercoagulable state after off-pump coronary artery bypass grafting: evidence, mechanisms and implications. Expert Rev Cardiovasc Ther. 2011;9:599-608.

9. Mannacio VA, Di Tommaso L, Antignan A, De Amicis V, Vosa C. Aspirin plus clopidogrel for optimal platelet inhibition following off-pump coronary artery bypass surgery: results from the CRYSSA (prevention of Coronary arteRY bypaSS occlusion After off-pump procedures) randomised study. Heart. 2012;98:1710-5.

10. Gurbuz AT, Zia AA, Vuran AC, Cui H, Aytac A. Postoperative clopidogrel improves mid-term outcome after off-pump coronary artery bypass graft surgery: a prospective study. Eur J Cardio-Thoracic Surg. 2006;29:190-5. 